\title{
Bioética e Educação: Concepção da Terminologia Bem- Estar-Animal por Estudantes do Ensino Básico
}

\section{Bioethics and Education: Conception of the Terminology Animal Welfare by Students of Basic Education}

\author{
Marta Luciane Fischer ${ }^{\circledR}$ Brasil \\ Ana Laura Diniz Furlan ${ }^{\circledR}$ Brasil
}

O rápido avanço tecnológico e cultural da humanidade tem resultado em sérios impactos ambientais, demandando novos paradigmas norteadores da sua relação com a natureza, principalmente, com os animais mantidos cativos por funções justificadas e para as quais não haja alternativas. Dessa forma, questionou-se como o termo bem-estar-animal tem sido disseminado nas mídias digitais, bem como a sua concepção por estudantes do ensino básico. Para tal, além da categorização do conteúdo divulgado em diferentes veículos da internet, foi realizada uma ação com estudantes do ensino fundamental e médio de escolas da rede pública e privada, envolvendo construção coletiva de conceitos, projeção de documentário e produção de material artístico e literário. Os resultados revelaram que a disseminação da terminologia bem-estar-animal ainda está associada a uma visão antropocêntrica e utilitarista, cuja maior ou menor valoração vinculase à representatividade e funcionalidade de determinados animais. A concepção dos estudantes refletiu o senso comum revelando a necessidade de apropriação do acesso às fontes de informação pela educação a fim de habilitá-los para apreender e processar o conteúdo. Assim, discute-se a importância de se pesquisar, aplicar e validar metodologias que associem a educação à bioética ambiental. Através da aplicação dessa ferramenta inovadora, busca-se promover a educação moral por meio da condução do estudante à compreensão da importância de saber ouvir, sem julgamentos, os argumentos dos todos os atores envolvidos em questões complexas. Desta maneira, podem ser pautadas em valores éticos globais e, por meio de atitudes reflexivas, críticas e responsáveis, ele possa desenvolver autonomia e espírito cooperativo para encontrar soluções consensuais e justas para as sociedades, para os animais, para a natureza, desta e de futuras gerações.

Palavras-chave: Bioética ambiental; biofilia; educação ambiental; educação moral; interação homem/natureza.

The fast technological and cultural advancement of humanity has resulted in serious environmental impacts, demanding new paradigms that guide their relationship with the nature, mainly with animals kept in captivity in order to perform justified functions and for which there are no alternatives. Thus, we questioned the animal-welfare terminology that has been disseminated in digital media, as well how students from 
basic education understand it. In this sense, besides the categorization of the content published on different internet vehicles, students from elementary and high schools in public and private schools participated in a series of activities: collective construction of concepts, projection of a documentary, and production of artistic and literary materials. The results show that the spread of aspects of the animal-welfare is still associated with an anthropocentric and utilitarian view whose higher or lower valuation is linked to the representation and functionality of certain animals. The students' view reflects common sense and reveals the need that education promotes the ownership of information sources in order to enable them to understand the content. Thus, we discuss the importance of producing, applying and validating methodologies that associate environmental education with environmental bioethics. Form such an innovative tool, we aim at supporting that moral education by guiding students to understand the importance of listening the arguments of all actors on complex issues without making previous judgments about them. In this way, students' choices might be guided by global ethical values and from reflective, critical and responsible attitudes, they might develop autonomy and cooperative spirit to find consensual and just solutions for society, for animals, for nature, in this and future generations.

Keywords: Biophilia; environmental bioethics; environmental education; interaction $\mathrm{man} /$ nature; moral education.

\section{Introdução}

A terminologia bem-estar-animal (BEA) é utilizada para caracterizar o estado físico e mental em que um animal se encontra em um determinado momento, resultante das possibilidades em atender suas demandas biológicas através do restabelecimento do equilíbrio homeostático, temporariamente alterado em decorrência da variação do seu ambiente interno e externo (Broom \& Fraser, 2010, Grandin \& Johnson, 2010). O termo passou a ser consolidado no final da década de 1960, com a divulgação do livro Animal Machines de Ruth Harrison que relatou a drástica situação da criação dos animais para alimentação no pós-guerra, mediante a demanda por carne com baixo custo de aquisição (Harrison, 1964). A publicação desencadeou a implementação de comissões para avaliação do grau de bem-estar dos animais de produção, subsidiando $a$ posteriori a fundação da ciência do BEA. Esta visa, além da elaboração de protocolos de diagnóstico, a promoção de inovação tecnológica nos sistemas de criação e no cativeiro (Broom \& Fraser, 2010). Embora a ciência do BEA tenha se iniciado com animais de produção, atualmente é aplicada na orientação do manejo de todos os animais mantidos cativos sob a tutela dos humanos para finalidades como: experimentação, aulas práticas, exposição em zoológicos ou espetáculos, auxiliares em serviços como guarda ou terapia e, até mesmo, para companhia (Broom \& Fraser, 2010, Grandin \& Johnson, 2010). Contudo, a definição exata do termo, bem como a ineficiência de tecnologia que ateste eficientemente o grau de BEA, todavia gera discrepâncias de concepções e condutas. 
Isto, mesmo diante de um posicionamento favorável da sociedade, dos órgãos gestores e dos políticos que conduziram a promulgação de leis que visam coibir os maus-tratos a animais como a Lei de crimes ambientais nº9.605 (Lei no 9.605, 1998) e a Lei Auroca $\mathrm{n}^{\circ} .11 .794$ (Lei no $11.794,2008$ ).

A história evolutiva da humanidade está intrinsicamente relacionada com a natureza, a qual além de suprir meios para sobrevivência física, também satisfaz demandas psicológicas e emocionais, caracterizando um mecanismo denominado de biofilia. Neste, se postula a existência de uma necessidade biológica, determinada geneticamente, dos seres humanos interagirem com os demais seres-vivos e processos naturais, sendo que a deficiência desse contato tem comprovadamente causado distúrbios biopsicossociais (Wilson, 1984). Os animais desde a gênese das sociedades humanas representam grande importância, seja como fontes de alimentos, na utilização de suas peles e óleos, na geração de força, em estudos e pesquisas científicas ou mesmo participando efetivamente na vida social das pessoas por meio de sua companhia. Neste contexto, animais como bois, ovelhas, cavalos, cães e gatos passaram por um processo denominado de domesticação através do estabelecimento de fortes e recíprocos vínculos afetivos com os homens. O processo decorreu de mudanças genéticas que promoveram a diminuição da distância de fuga e a aceitação dos humanos como integrante do seu grupo social (Grandin \& Johnson, 2010). Uma recente pesquisa aponta que cerca de $80 \%$ das famílias brasileiras possui algum tipo de animal de companhia, sendo $63 \%$ cães, os quais têm sido incorporados como uma opção para substituição de filhos, igualando o Brasil à países como Japão e Estados Unidos (IBGE \& ABINPET, 2013).

As sociedades contemporâneas, mesmo dependentes dos animais, têm demandado mudanças nos paradigmas norteadores de condutas direcionadas aos mesmos, mostrando-se intolerantes à determinadas práticas e exercendo papel ativo na denúncia e reivindicação por legislações e fiscalizações mais severas (Fischer \& Tamioso, 2013). Nesse contexto, destaca-se a tutela responsável que representa o compromisso com a dignidade do animal (Santana, Macgregor, Souza, \& Oliveira, 2004), cuja efetivação demanda a superação de divergências sobre o direito animal, pelo direito civil, penal e ambiental e nas esferas práticas do agronegócio, entretenimento, controle de zoonoses, pesquisas e aulas práticas desnecessárias.

Outro aspecto comumente associado ao BEA é a senciência, ou seja, a capacidade do animal de sentir dor, sofrimento ou prazer (Grandin \& Johnson, 2010). Diante dessa concepção, grupos defensores da causa animal passaram a endossar a ideia de que os animais devem ser tratados como sujeitos e não como objeto do direito. Entretanto, o anseio de condições igualitárias para os animais está distante de se concretizar, pois o afastamento afetivo entre os homens e os demais animais fundamentou os princípios da ética antropocêntrica utilitarista, exaltando os interesses do ser humano nas decisões éticas, valorizando a supremacia da razão, cujo poder reflete sobre a integridade da natureza e dos animais (Levai, 2014). A ética utilitarista apoia o uso de animais apenas em situações extremamente necessárias, para as quais não haja alternativas. Mesmo 
assim, pontua que os homens detêm o dever moral de não causar dor ou sofrimento, promovendo elevados graus de BEA (Singer, 2000; Levai, 2014). Esta concepção passou a se consolidar com a transformação de uma sociedade menos antropocêntrica e utilitarista na direção de uma visão biocêntrica (Levai, 2014), cujo status de atribuição moral está centrado na vida, independente de se o animal possui ou não consciência, linguagem ou razão. Neste contexto, o homem não é visto como ser supremo, mas apenas como mais uma espécie dentre tantas outras componentes da teia da vida. Na direção contrária, tem-se os defensores da ética abolicionista disseminada por filósofos como Regan (1983) e Francione (2013), que reivindicam o fim imediato da exploração animal, independentemente de para qual seja a finalidade, defendendo a ideia de que os animais, além do interesse em não sofrer, têm interesse em viver, logo não há justificativa para privá-los desse direito.

A questão da ética animal requer discussões associadas não só a contextos de educação ambiental, mas a novos contextos como o da bioética ambiental em função do aumento de complexidade dos problemas geradores de vulnerabilidades resultantes de concomitantes decisões tomadas por inúmeros agentes morais, subsidiados por valores e interesses próprios (Capilé, Lima, \& Fischer, 2014; Fischer, Renk, Rodrigues, \& Bordini, 2014). O papel da bioética incide na promoção de uma ponte entre as ciências naturais e humanísticas, promovendo o diálogo entre os diferentes atores envolvidos em uma questão ética complexa, global e plural. O ambiente escolar, tendo a educação ambiental como meio, visa conduzir o estudante à compreensão da importância de saber ouvir sem julgamentos os argumentos do outro, e através da reflexão encontrar uma solução consensual e justa para as sociedades, para os animais, para a natureza, desta e de futuras gerações.

O estudo dos animais no ensino básico está disposto no eixo das ciências naturais nos Parâmetros Curriculares Nacionais - PCN(Ministério da Educação, 1997), tendo por objetivo ensinar conhecimentos sobre taxonomia, adaptação ao ambiente, padrões biológicos, relação entre os seres vivos, matéria e energia, biologia e a preservação. A educação ambiental é apontada como meio transversal de discutir a necessidade de reconstrução da relação homem/natureza, desmistificando a ideia de soberania dos seres humanos (Ministério da Educação, 1997). Segundo este documento, o processo de educação deve acontecer de forma prazerosa e que sensibilize os alunos sobre a necessidade de preservação do ambiente. As mídias digitais se constituem como poderosos meios de comunicação contemporâneos, permitindo ao estudante e ao cidadão a conexão com uma ampla rede de informações (Moran, 1997; Fischer, Caires, \& Colley, 2015). Contudo, a inerente democracia associada à interatividade desse meio de comunicação tem gerado inúmeros atrasos ao processo de educação, uma vez que muitos conteúdos são mal elaborados gerando interpretações incompletas e errôneas. Isto demanda uma análise minuciosa do que está sendo acessado pelos estudantes e, dessa forma, pode direcionar seu processo de aprendizagem (Fischer, Caires, \& Colley, 2015). Desta forma, as questões que guiaram o presente estudo foram: como a terminologia 
bem-estar-animal tem sido disseminada pelas mídias digitais? Qual é a concepção dos jovens estudantes de diferentes realidades escolares a respeito dessa temática? Para responder essas questões foram testadas as seguintes hipóteses: a) a concepção do estudante do ensino básico tende a refletir o senso comum; b) a existência de diferentes meios de transmissão da informação permite alcançar um público plural, mas que deve ser instrumentalizado para inserir tais informações no contexto de comunicação inerente à educação; c) a concepção da temática é dependente da maturidade e nível socioeconômico do estudante; d) a complexidade, pluralidade e amplitude da temática demanda a intervenção da educação através de ferramentas inovadoras como bioética ambiental a fim de favorecer o desenvolvimento de habilidades dos estudantes para refletir sobre os valores igualitários a todos os seres vivos.

\section{Materiais e Método}

\section{Avaliação das informações veiculadas na Internet}

A primeira etapa da pesquisa visou categorizar a utilização da terminologia BEA nas mídias digitais. Para tal foram analisadas as primeiras 300 páginas recuperadas através do buscador Google.com e na rede de relacionamento Facebook. No buscador, utilizado sem login do usuário, os conteúdos foram recuperados, de fevereiro de 2012 a dezembro de 2014, através da utilização do termo bem-estar-animal. As informações foram categorizadas segundo a técnica de análise de conteúdo semântico de Bardin (2004), a partir da organização das informações em planilhas eletrônicas, nas quais se considerou a origem da informação (governo, empresa, organizações não governamentais - Ongs) e a ferramenta de veiculação (site, portal, blog, imprensa, empresa). Os grupos disponíveis na rede social foram recuperados utilizando-se a expressão bem-estar-animal sendo categorizados considerando conforme a finalidade do grupo, os animais abordados e o número de compartilhamentos.

\section{Análise da figura de animais divulgados por usuários na rede social}

Para esta etapa foi utilizada a rede social Facebook por meio da caracterização da utilização de imagens de animais como coadjuvantes na comunicação. Foi obtida a participação de sete proprietários de perfis sendo: uma bióloga formada e professora, uma graduanda em Biologia, um estudante de engenharia elétrica, um estudante do ensino médio, um fotógrafo, um historiador e um matemático. De cada perfil foram arquivadas 100 postagens, totalizando 700 imagens que envolviam animais cujo contextos da sua utilização foram transcritos em planilhas eletrônicas e categorizadas segundo técnica de Bardin (2004). As categorias resultantes após o agrupamento foram: a) oferecimento para adoção; b) decorativo: animais sendo utilizados em cartões de datas comemorativas; c) perdidos: divulgação e informações sobre animais perdidos; d) denúncia: animais sofrendo maus-tratos; e) estimação: animais domésticos de estimação com ou sem o tutor; e) evento: animais sendo utilizados como propaganda em eventos; f) informação: 
sobre saúde animal; g) natureza: animais selvagens; h) objeto de consumo: animais utilizados em comércio; i) sensibilização: animais sendo utilizados em campanhas em favor dos seus direitos.

\section{Avaliação da percepção de alunos do ensino básico a respeito da terminologia bem-estar-animal}

O estudo foi conduzido durante o primeiro trimestre de 2013 com estudantes de um colégio da rede particular de ensino e de um colégio público. Com intuito de avaliar a influência de maturidade na percepção do tema BEA, o grupo de estudo foi composto de duas turmas em cada escola: alunos do ensino fundamental ( $7^{\circ}$ ano) e ensino médio ( $2^{\circ}$ ano). Para a seleção das turmas, foi avaliado o conteúdo trabalhado, conforme proposto pelo plano curricular. A avaliação contou com a participação de 120 jovens, sendo: 60 estudantes do ensino fundamental (30 de escola pública e 30 de escola particular) e 60 alunos do ensino médio (30 de escola pública e 30 de escola particular). A primeira etapa do estudo consistiu no diagnóstico da concepção do termo BEA. Para tal, a proposta foi apresentada aos estudantes juntamente com o termo de consentimento livre e esclarecido (TCLE). Após a entrega do TCLE assinado, o tema foi introduzido através da explicação do conceito de BEA, e então, procedida análise qualitativa em grupo focal (Ressel et al., 2008). Para tal, foram lançadas três perguntas, e as respostas transcritas no quadro, para que a percepção fosse coletivamente construída. Para cada questão foi realizada a quantificação dos alunos que concordavam ou não com as assertivas: a) acredito ser correto os animais dependerem uns dos outros para sobreviverem na natureza; b) acredito ser correto o homem depender dos animais para suas necessidades biológicas, tecnológicas e econômicas (com listagem dos tipos de uso); c) acredito que existam diferenças na forma como os animais interagem entre si na natureza e na forma que o homem trata os animais (com listagem das diferenças).

Após a realização do grupo focal, foi projetado o documentário "Animais seres senscientes", produzido pela Sociedade Mundial de Proteção Animal (WSPA, 2011), com objetivo de conduzir os estudantes a uma reflexão sobre a interação entre os seres humanos e os animais não humanos. Logo em seguida, foi solicitado aos alunos que eles produzissem conteúdos para confecção de um hipotético material de divulgação para sociedade, podendo ser desenhos, textos, poemas, estando o estudante livre quanto ao que produzir a respeito dos temas considerados mais necessários envolvendo o conteúdo trabalhado. Esse material foi categorizado em uma planilha eletrônica segundo a metodologia de análise de conteúdo (Bardin, 2004). Esta análise resultou nas categorias: a) animais: doméstico (companhia, trabalho, produção), experimental ou selvagem; b) nome popular do animal representado; c) relação representada (afetividade, agressividade, ambos); d) presença de pessoas no desenho; e) utilização de cores; f) tipo de ambiente (doméstico e natureza); g) condição do animal (livre ou cativo); h) utilização de texto; i) conteúdo abordado no texto. 


\section{Procedimentos Éticos e Estatísticos}

O projeto foi aprovado pelo Comitêde Ética em Pesquisa da Pontifícia Universidade Católica do Paraná (parecer nº. 157.902) e os TCLEs arquivados no Laboratório Núcleo de Estudos do Comportamento Animal. A homogeneidade da representatividade das categorias de utilização dos animais como coadjuvantes na comunicação, a categorização das respostas do grupo focal e das imagens e textos utilizados no material de sensibilização foi inferida por meio da aplicação do teste de aderência denominado Goodness of fit $\left(\mathrm{G}_{\text {Test }}\right)$. Este teste avalia, com maior sensibilidade e acurácia, se as frequências das categorias de uma determinada variável ocorreram ao acaso, ou seja, em igual proporção, ou se determinadas categorias foram significativamente mais frequentes na amostra avaliada. Para tal, foi considerada a significância de $95 \%$, ou seja, para o resultado do teste ser aceito como verdadeiro, admitiu-se uma probabilidade de erro menor do que $5 \%(\mathrm{P}<0,05)$.

\section{Resultados}

\section{Avaliação das informações veiculadas nas mídias digitais}

$\mathrm{O}$ termo bem-estar-animal foi veiculado principalmente por portais igualmente originários dos três setores econômicos e da academia, cujo padrão foi mantido ao longo dos anos, detendo prioritariamente foco dos conteúdos nos animais de companhia. Por outro lado, as parcerias com outros órgãos e entidades, associação com rede social e dissociação com comércio, foram mais evidentes nas amostragens mais recentes (Tabela 1).

De 2011 a 2015 foram criadas 100 páginas no Facebook com a temática BEA, sendo $36 \%$ relacionadas à clínicas veterinárias e $12 \%$ a ONGs. Os compartilhamentos abordaram: eventos (25\%), notícias relacionadas à educação e promoção da ciência do bem-estar (21\%), doação, castração e denúncias (25\%), estando os mesmos associados a animais de produção e de companhia.

Tabela 1. Frequência relativa (\%) da categorização dos conteúdos com abordagem da temática bem-estar animal, veiculadas na Internet de 2009 á 2014

\begin{tabular}{llccccccc} 
Categorias & Variáveis & 2009 & 2010 & 2011 & 2012 & 2013 & 2014 & Total \\
\hline \multirow{6}{*}{ Fontes } & Acadêmico & 13 & 31 & 31 & 22 & 26 & 28 & 25 \\
& Privado & 39 & 24 & 25 & 25 & 32 & 34 & 30 \\
& Governo & 16 & 25 & 21 & 35 & 28 & 25 & 25 \\
& ONG & 32 & 25 & 21 & 18 & 35 & 21 & 21 \\
\multirow{5}{*}{ Privado } & & & & & & & & \\
& Blog & 32 & 20 & 46 & 22 & 33 & 35 & 28 \\
& Portal & $52^{*}$ & 30 & 29 & 47 & $45^{*}$ & 45 & $43,5^{*}$ \\
& Site & 14 & 48 & 23 & 30 & 35 & 37 & 28
\end{tabular}




\begin{tabular}{|c|c|c|c|c|c|c|c|c|}
\hline Categorias & Variáveis & 2009 & 2010 & 2011 & 2012 & 2013 & 2014 & Total \\
\hline \multirow{6}{*}{ Animais } & Abandonados & 13 & 20 & 37 & 0 & 35 & 25 & 16 \\
\hline & Silvestres & 19 & 20 & 19 & 29 & 25 & 29 & 22 \\
\hline & Companhia & $23^{*}$ & $20^{*}$ & $21^{*}$ & $28^{*}$ & $38^{*}$ & $42^{\star}$ & $52^{*}$ \\
\hline & Entretenimento & 0 & 1 & 1 & 0 & 2 & 3 & 1,7 \\
\hline & Produção & 27 & 30 & 10 & 22 & 34 & 30 & 26 \\
\hline & Todos & 20 & 8 & 10 & 20 & 52 & 43 & 17 \\
\hline \multirow{2}{*}{ Parcerias } & Não & 49 & 36 & 64 & 52 & 43 & 37 & 42 \\
\hline & Sim & 49 & 63 & 34 & 46 & $57^{\star}$ & $63^{*}$ & $57^{*}$ \\
\hline Redes & Não & 36 & 54 & 62 & 36 & 33 & 27 & 38 \\
\hline sociais & Sim & 62 & 44 & 36 & 62 & $67^{*}$ & $73^{*}$ & $62^{*}$ \\
\hline \multirow{2}{*}{ Venda } & Não & 29 & 31 & 56 & 87 & $62^{*}$ & $84^{*}$ & $61^{*}$ \\
\hline & Sim & 69 & 68 & 42 & 11 & 38 & 16 & 40 \\
\hline
\end{tabular}

A homogeneidade dos valores relativos às variáveis de cada categoria dos conteúdos foi atestada através da aplicação do teste de aderência $G_{\text {test }}$ sendo os valores significativamente mais representativos acompanhados de asterisco $\left(^{*}\right)$.

\section{Análise do uso de imagens de animais nas redes sociais}

A avaliação das imagens contendo animais elucidou pouca uniformidade entre os perfis analisados, embora apresentaram maior representação: a associação de imagens de animais como elemento da natureza, como decorativo de outros elementos de comunicação e como auxiliar para despertar sensibilidade. Na maioria dos perfis verificou-se predomínio de determinadas categorias, tais como informação para biologia, animais de estimação para biologia e matemática, sendo os perfis da biologia, história e matemática o que apresentaram funções mais diversificadas (Figura 1).

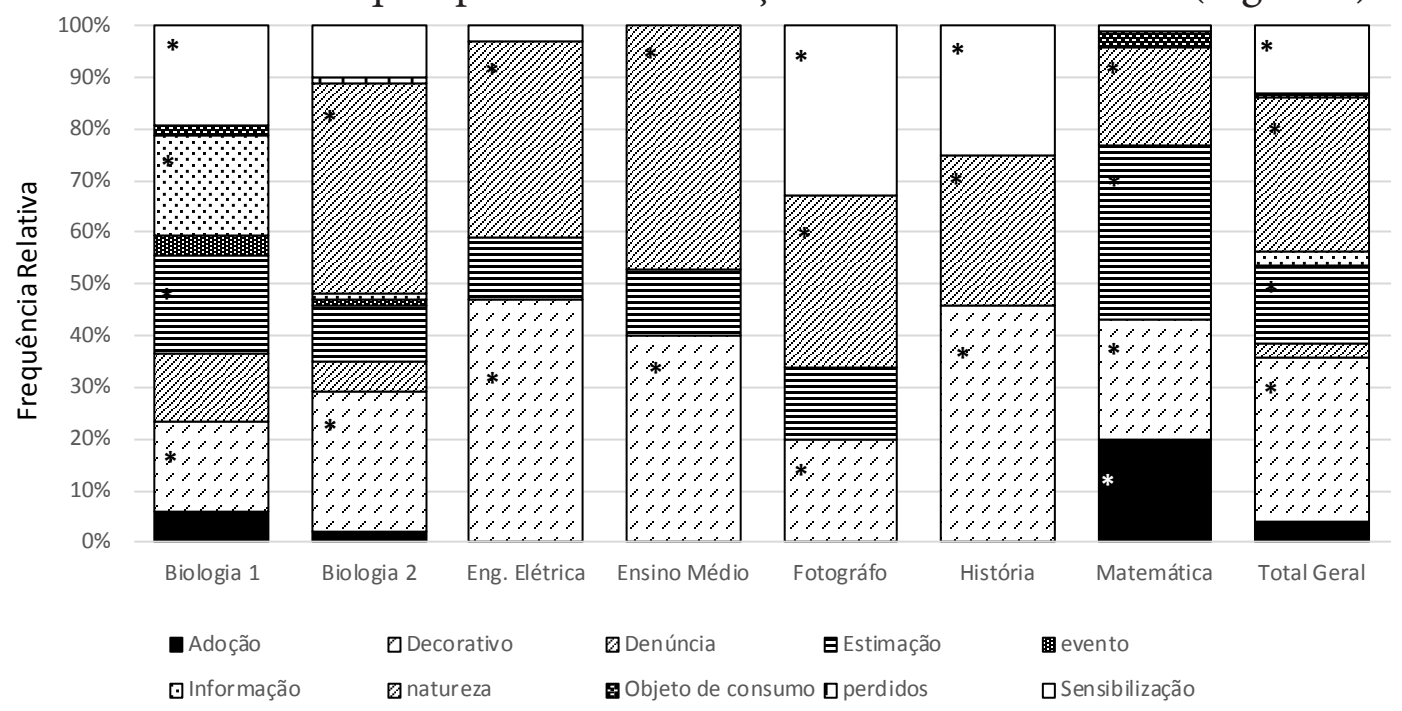

Figura 1. Frequência relativa das imagens envolvendo animais classificadas em: adoção; informação; decorativo; denúncia; objeto de consumo; estimação; perdidos; evento e sensibilização divulgados por usuários da rede social Facebook, entre perfis de engenharia elétrica, ensino médio, fotógrafo, história, matemática e dois perfis pertencentes a Biologia. A homogeneidade das categorias em cada perfil e no total foi testada através do teste de aderência $\mathrm{G}_{\text {test }}$ sendo os valores significativamente maiores $(\mathrm{P}<0,05)$ estão acompanhados de asterisco $\left.{ }^{*}\right)$. 


\section{Concepção de estudantes do ensino básico a respeito do termo Bem- Estar-Animal}

A maioria dos estudantes se posicionou atribuindo idoneidade no fato dos animais dependerem uns dos outros na natureza (Tabela 2), levantando argumentos como: a) " $E$ necessário para a reprodução, alimentação, ganho de território, companhia”, apontaram "que os animais cooperam entre si"; b) "É da natureza do animal eles dependerem uns dos outros para a sobrevivência"; c) "Quando acontece a predação, ajudam no controle populacional". Poucos alunos não se manifestaram sobre esse questionamento. Quase a totalidade dos estudantes consideraram correto o homem também depender dos animais para suas necessidades biológicas, tecnológicas e econômicas (Tabela 2) e endossaram o uso de animais para saciar as necessidades de alimentação e testar novos medicamentos. Os alunos que não concordaram, alegaram que: a) "A necessidade de o homem depender dos animais é cruel, para diversos fins". Contudo todos os estudantes reconheceram distinção da interação estabelecida entre os animais na natureza daquelas estabelecidas entre seres-humanos e natureza, diferença de tratamento entre homens e animais, destacando os comentários: a) "os animais não maltratam por prazer"; b) "É uma atitude do ser humano"; c) "O homem é o único capaz de abandonar um animal, por não querer cuidar". A exploração e maus-tratos foram outros temas destacados pelos alunos.

Tabela 2. Frequência relativa (\%) de resposta dos alunos do $7^{\circ}$ ano do ensino fundamental e $2^{\circ}$ ano do ensino médio de colégio público particular e público a respeito dos questionamentos discutidos na dinâmica do grupo focal

\begin{tabular}{|c|c|c|c|c|c|c|}
\hline & \multirow{2}{*}{\multicolumn{2}{|c|}{$\begin{array}{l}\text { Questão } 1 \\
\text { É correto os animais } \\
\text { dependerem uns dos } \\
\text { outros para sobreviverem } \\
\text { na natureza? }\end{array}$}} & \multirow{2}{*}{\multicolumn{2}{|c|}{$\begin{array}{l}\text { Questão } 2 \\
\text { É correto o homem } \\
\text { depender dos animais } \\
\text { para suas necessidades } \\
\text { biológicas, tecnológicas e } \\
\text { econômicas? }\end{array}$}} & \multirow{2}{*}{\multicolumn{2}{|c|}{$\begin{array}{l}\text { Questão } 3 \\
\text { Existem diferenças na } \\
\text { forma como os animais } \\
\text { se interagem entre si na } \\
\text { natureza e na forma que o } \\
\text { homem trata os animais? }\end{array}$}} \\
\hline & & & & & & \\
\hline & Concordam & Discordam & Concordam & Discordam & Concordam & Discordam \\
\hline $7^{\circ}$ Particular & $83^{*}$ & 16 & $90^{*}$ & 10 & $100^{*}$ & 0 \\
\hline $7^{\circ}$ Público & $80^{\star}$ & 20 & 50 & 40 & $100^{*}$ & 0 \\
\hline $2^{\circ}$ Particular & $100^{*}$ & 0 & $96^{*}$ & 33 & $100^{*}$ & 0 \\
\hline $2^{\circ}$ Público & 60 & 40 & $96^{*}$ & 3 & $100^{*}$ & 0 \\
\hline
\end{tabular}

A homogeneidade dos valores relativos às variáveis de cada categoria dos conteúdos foi atestada através da aplicação do teste de aderência $G_{\text {test }}$ sendo os valores significativamente mais representativos acompanhados de asterisco $\left(^{*}\right)$.

Os desenhos utilizados na elaboração do hipotético material de sensibilização, foi caracterizado pela representação de afetividade, animais domésticos, principalmente de produção e companhia, tais como cachorro, gato e porco. Os animais selvagens, por sua 
vez foram percebidos e representados por pássaros, leão e macaco. A maioria dos alunos não representou pessoas. Denúncia, agressão e igualdade também foram retratados pelos estudantes (Tabela 3 ).

Os textos abordaram assuntos como:

Não façam os animais sofrerem, eles também têm sentimentos. Como os porcos são colocados em um chão de cimento mas gostam de cavar. As galinhas ficam em gaiolas que não conseguem abrir suas asas. Pássaros ficam presos perdem sua liberdade se cortam suas asas;

Os animais precisam ter seu habitat natural, sem maltrato. Eles precisam ser livres, temos que cuidar bem deles, porque se maltratarmos os animais, eles guardam esse acontecimento, que pode deixá-los tristes ou com raiva;

Os cachorros são amigos do ser humano, eles nos acompanham a qualquer lugar. $O$ cachorro tem sempre a característica do dono, por exemplo: se o dono for alegre, o cachorro também é alegre.

Alguns textos também abordaram a sensibilização:

Olhe no fundo dos olhos de um animal e, por um momento troque de lugar com ele. A vida dele se tornará tão preciosa quanto a sua, e a sua se tornará tão vulnerável quanto a dele.

Tabela 3. Frequência relativa da categorização de desenhos envolvidos na produção do hipotético material de divulgação dos estudantes do sétimo ano e segundo $(A=$ particular e $B$ = público) após a dinâmica e projeção do documentário

\begin{tabular}{llccccc}
\hline Parâmetro & Categoria & $\mathbf{7}^{\mathbf{a}} \mathbf{A}$ & $\mathbf{7}^{\mathbf{a}} \mathbf{B}$ & $\mathbf{2}^{\mathbf{a}} \mathbf{A}$ & $\mathbf{2}^{\mathbf{a}} \mathbf{B}$ & Total \\
\hline \multirow{3}{*}{ Relação } & Afetividade & $64^{*}$ & 69 & $69^{*}$ & 61 & $58^{*}$ \\
& Agressividade & 21 & 45 & 13 & 38 & 29 \\
& Ambos & 13 & 13 & 0 & 0 & 9 \\
\multirow{2}{*}{ Tipo } & & & & & \\
& Doméstico & 58 & $90^{*}$ & $84^{*}$ & 46 & $62^{*}$ \\
& Não doméstico & 41 & 9 & 15 & 46 & 32 \\
Categoria dos & Companhia & $64^{*}$ & 21 & $46^{*}$ & $83^{*}$ & $47^{*}$ \\
Domésticos & Trabalho & 8 & 4 & 7 & 16 & 7 \\
& Produção & 32 & $69^{*}$ & $46^{*}$ & 0 & $44^{*}$ \\
& Pesquisa & 0 & 4 & 0 & 0 & 1 \\
& Cachorro & 28 & 14 & 15 & 28 & 14 \\
& Gato & 25 & 7 & 23 & $57^{*}$ & $23^{*}$ \\
Domésticos & Porco & 18 & 28 & 23 & 0 & 14 \\
& Vaca & 9 & 21 & $30^{*}$ & 0 & 12,5 \\
& Galinha & 12 & 21 & 0 & 0 & 9 \\
& Cavalo & 6 & 3 & 7 & 14 & 6 \\
& Coelho & 0 & 3 & 0 & 0 & 0,7
\end{tabular}




\begin{tabular}{llccccc}
\hline Parâmetro & Categoria & $\mathbf{7}^{\mathbf{a}} \mathbf{A}$ & $\mathbf{7}^{\mathbf{a}} \mathbf{B}$ & $\mathbf{2}^{\mathbf{a}} \mathbf{A}$ & $\mathbf{2}^{\mathbf{a}} \mathbf{B}$ & Total \\
\hline & Cervo & 0 & 50 & 0 & 0 & $13^{*}$ \\
& Foca & 0 & 0 & 0 & 16 & 4 \\
& Girafa & 4 & 0 & 0 & 0 & 1 \\
& Leão & 27 & 0 & 0 & 0 & $6,8^{*}$ \\
& Pássaro & 27 & 50 & 25 & 33 & $34^{*}$ \\
& Tigre & 9 & 0 & 0 & 0 & 2,5 \\
Não-domésticos & Lobo & 4 & 0 & 0 & 0 & 1 \\
& Macaco & 4 & 0 & 25 & 16 & 11 \\
& Tatu & 0 & 0 & 25 & 0 & 6 \\
& Tartaruga & 0 & 0 & 25 & 0 & 6 \\
& Panda & 0 & 0 & 0 & 16 & 4 \\
& Peixe & 9 & 0 & 0 & 0 & 2,5 \\
& Cobra & 4 & 0 & 0 & 0 & 1 \\
& Tucano & 0 & 0 & 0 & 16 & 4 \\
& Urso & 9 & 0 & 0 & 0 & 2,5 \\
\hline
\end{tabular}

A homogeneidade dos valores relativos às variáveis de cada categoria dos conteúdos foi atestada através da aplicação do teste de aderência $G_{\text {test }}$ sendo os valores significativamente mais representativos acompanhados de $\operatorname{asterisco}\left({ }^{*}\right)$.

\section{Discussão}

O presente estudo elucida como a temática do BEA vem sendo veiculada e incorporada por estudantes do ensino básico da rede pública e privada, evidenciando a necessidade de se trabalhar a educação ambiental associada à bioética ambiental. Isto se justifica porque a bioética ambiental se mostra como uma ferramenta eficaz na promoção do diálogo entre diferentes atores envolvidos em questões complexas, cujas escolhas, deverão ser pautadas em valores éticos globais e através de um pensamento crítico e responsável.

\section{Veiculação da temática BEA pelas mídias digitais}

A uniformidade temporal da veiculação da terminologia BEA, bem como do tratamento proporcional pelos segmentos público, privado, acadêmico e do terceiro setor, caracterizam a democratização da disseminação de conhecimento. Esta abrangência permite o alcance de diferentes públicos nos meios digitais, tal como atestado por Fischer (2013) e Fischer, Caires, \& Colley (2015) ao avaliarem a utilização do meio digital para divulgação de conteúdo de etologia e sobre o caramujo africano. Os autores alertaram que a concepção e aplicação de um determinado conhecimento devem estar condicionados a processos cognitivos individuais que atendam às demandas específicas do público alvo. É notório que a tecnologia digital possibilita o uso de linguagem comum e simplificada, por meio da exploração de textos e imagens que não exigem conhecimento científico para estabelecer o canal de transmissão da informação. Tal fato endossa o desenvolvimento de meios para que diferentes segmentos da sociedade se tornem protagonistas na geração e mediadores na perpetuação da informação, e de maneira igualitária, como atestado no presente estudo. Contudo, Fischer, Caires, \& Colley (2015) observaram que embora as informações sobre a espécie de interesse médico se tornaram mais democráticas com a 
internet, muitas destas não são fidedignas, ou podem ser manipuladas cumprindo outras funções, tais como econômicas e políticas. Como na temática do BEA, pode conduzir para percepções distorcidas de como se relacionar com os animais. Além disso, a expansão de ferramentas que facilitam a publicação, sem requerimento de um rigor científico e maiores conhecimentos técnicos, acaba gerando conhecimento disperso e, por muitas vezes, falho e ineficaz. Araujo, Tizioto, Caluzi, Batisteti, e Andrade (2010) consideraram também o desafio de traduzir um conhecimento científico de modo que seja compreensível por um público não especializado. Segundo os autores, caso essa transmutação não seja bem estruturada é plausível conduzir a uma simplificação, constituída por distorções conceituais, resultando em uma visão mistificada da ciência. Consequentemente, informações errôneas ou incompletas são transmitidas e compartilhadas tornando, conforme atenta Sabbatini (2001), um grande desafio para a educação contemporânea. Embora a humanidade esteja em um momento ímpar em termos de acesso à informação, Sá e Moraes (2011) chamaram a atenção para que a real compreensão das mensagens geradas e propagadas ainda está limitada a uma minoria econômica e intelectualmente privilegiada. De acordo com Araujo, Tizioto, Caluzi, Batisteti, e Andrade(2010), as desigualdades no acesso às informações demandam, assim, a apropriação pela educação. Esta, por meio do exercício da criatividade e criticidade deve oportunizar ao estudante meios de transformá-lo em cidadão multiplicador e gerador de saberes. Sendo que estes conhecimentos devem tanto atender às demandas individuais, quanto muni-lo de ferramentas que os habilitem na formação de opinião e no protagonismo, além de promover inserção social. Especificamente, com relação ao BEA, devido à diversidade de conteúdo e representações biopsicossociais, é fundamental que o educador tenha conhecimento prévio do conteúdo disponível para o estudante e o oriente a utilizar tais informações de forma a otimizar a sua pesquisa. Para tal, a efetivação da alfabetização tecnológica, referida nos PCNs e diretrizes curriculares como tema transversal, e consequente promoção de sua inserção social e democratização do saber, demanda, além da capacitação do docente (Mantovani, 2006), o apoio de políticas públicas que incentivem e promovam a aplicação dessas tecnologias de informação e comunicação (TICs) (Bevort \& Belloni, 2009). Desta forma, concorda-se com Vieira, Silva, Dolino, Silva e Silva (2011) quando afirmam que a inerente diversidade de aplicações das TICs e as finalidades para as quais são direcionadas demandam a intervenção da educação na capacitação da autonomia do estudante e futuro cidadão, tanto na responsabilidade na geração da informação, quanto na capacidade reflexiva e interpretativa da mesma.

\section{A atuação das ONGS e os temas de BEA}

A atuação das ONGs na disseminação de conteúdos envolvendo temas de BEA equivaleu aos meios acadêmicos e governamentais caracterizando a mobilização social na participação do processo educativo não-formal e, consequentemente, demandado apropriação pela educação. Esta evidência corrobora as afirmativas de Herculano (2000) e Ciampi (2005) sobre as OGNs exercerem uma função fundamental para o 
desenvolvimento do questionamento crítico e responsável para questões ambientais e sociais, e as de Barzano (2009), segundo quem cabe às mesmas um papel de mantenedoras de uma educação ambiental não-formal. Para os autores, além dos conteúdos trabalhados pelas ONGs estarem disponíveis nos meios digitais, geralmente apresentam linguagem de fácil assimilação, especialmente na questão do BEA, no qual se apropriam da função de sensibilização e conscientização da sociedade para causa animal. Entretanto, Gohn (2009) destaca que este novo canal de comunicação é pouco conhecido tanto da população quanto da maioria das instituições de ensino. A existência de um espaço ambíguo de atuação das ONGs no campo educativo é atestada por Russo (2013), ressaltando que as mesmas não devem suprir apenas carências que deveriam ser obrigação do Estado, mas também disponibilizar espaços de resistência, discussão da realidade social e reflexão sobre o papel da escola na construção e fortalecimento de uma educação mais comprometida com as demandas sociais. Neste contexto, a escola pode e deve (i) se apropriar da disponibilidade desse canal de comunicação social para inserir os estudantes em um universo de protagonismo social; e (ii) orientá-los a ouvir e refletir sobre os diferentes posicionamentos existentes, enriquecendo seu repertório de conhecimento, especialmente relevante nas questões de BEA que envolvem diferentes animais utilizados para uma gama de finalidades.

\section{Os blogs e divulgação da terminologia BEA}

A homogeneidade na utilização dos diferentes meios de organização de informação disponíveis na Internet reforça a associação da divulgação da terminologia BEA para diferentes públicos, os quais além dos objetivos distintos, usam a internet de forma específica. Dentre esses veículos deve-se dispensar uma atenção especial aos blogs, cuja utilização foi próxima a de portais e sites, sugere a utilização de novas tecnologias de informação e comunicação pela educação, cuja dinamicidade e poder de comunicação se constitui de um instrumento na construção de saberes como atestado por Araújo (2009), Fischer (2013) e Fischer, Caires, e Colley (2015). Para Araújo (2009), Ammann (2011) e Fischer (2013), o blog, webblog ou caderno digital tem se pronunciado em diferentes contextos sociais e educativos diante da sua acessibilidade, facilidade de produção e atualização, não demandando conhecimentos específicos em informática, ou mesmo domínio do conteúdo. O blog pode ser utilizado tanto como ferramenta de aquisição de informação, quanto de geração e disseminação, cuja eficiência no ensino básico pode refletir aquela atestada no ensino superior por Fischer (2013). Neste contexto, o blog tem sido consolidado tanto como alternativa do estudante construir competências técnicas de domínio de canais de comunicação, que muito provavelmente serão fundamentais para sua atuação profissional, quanto na sua auto-concepção como protagonista na geração de opinião e disseminação de novos paradigmas éticos e morais. Segundo Araújo (2009), a educação não pode ficar alheia, marginalizada ou obsoleta diante do "dilúvio informacional" disponível e que demanda adaptações tanto do docente quanto do estudante, na busca de uma atuação inter- e transdisciplinar. 


\section{A temática BEA na mídia digital relacionada a animais de companhia e de produção}

$\mathrm{O}$ fato de a temática BEA na mídia digital estar relacionada principalmente à animais de companhia e de produção sugere tanto a existência de assimetria nas valorações aos diferentes grupos de animais, quanto uma preocupação genuína da necessidade de se oferecer melhores condições de vida para os animais mantidos cativos. Ressalva-se que o presente estudo detectou nos últimos anos um aumento da associação entre interesses comerciais, desenvolvimento de parcerias e interligação de diferentes meios de informação, fato que leva à expectativa da apropriação pelo setor econômico. Neste cenário identifica-se a utilização de princípios éticos antropocêntricos como intermediadores de decisões direcionadas aos animais endossada diante da evidente dependência dos mesmos, seja para alimentação, como fonte de trabalho, entretenimento, esportes e conforto emocional. Além disso, o bem-estar da humanidade e o suprimento de suas necessidades biológicas e tecnológicas têm sido aceitos como justificativas para manutenção de determinadas espécies cativas e sobre domínio. Contudo, a visão utilitarista disseminada por Singer (2000), e que deve ser trabalhada na escola, endossa o uso de animais para funções para as quais, todavia não há alternativas, clamando pela conduta ética ao promover as melhores condições possíveis para promoção do BEA ao evitar a dor e o sofrimento.

Desta forma, torna-se função da escola debater essas questões, uma vez que interação com os animais e com a natureza é uma realidade com a qual os estudantes se deparam diariamente. Logo, devem ser orientados a refletir sobre suas decisões, sobre quais valores e interesses estão considerando e se os mesmos são ou não legítimos e justos para todos os envolvidos. Dentre as inúmeras questões de interesse da criança e do adolescente destaca-se a relação com os animais de companhia. Mesmo diante de argumentos de que muitos animais são humanizados o suficiente para serem considerados membros da família, Dal-Farra (2004) ressalva a necessidade de preocupação com seu real bem-estar. Bauman (2004) alerta que o mercado consumista transmite a mensagem utilitarista e de valor monetário aos animais, permeando, assim, a ideia de que é possível comprar o amigo ideal, cujo valor pode ser reavaliado caso o animal não se comporte conforme o esperado, ou passe a incomodar a rotina da família. $\mathrm{O}$ abandono de animais não é reprimido, mesmo diante de uma óbvia substituição de filhos por cães no Brasil (IBGE, \& ABINPET (2013) conduta esta fortemente apoiada em costumes culturalmente perpetuados que devem ser balizados por novos paradigmas incorporados na infância. Robis e Nassaro (2013) apresentaram dados que atestam que criminosos perigosos, na sua infância, praticaram maus-tratos contra animais. Os autores sugerem que este comportamento pode ser utilizado como um indicativo de um potencial risco, o qual deve ser mitigado, assim que detectado. Essa intervenção deveria funcionar como uma medida preventiva, através de processos de orientação, educação e monitoramento da criança e seu ambiente social. Logo, soma-se mais este motivo para a escola avaliar as concepções e relações estabelecidas entre os educandos e os animais. 


\section{A visão utilitarista dos animais}

A visão utilitarista dos animais identificada no presente estudo foi reforçada pela análise do uso de sua imagem com a finalidade de decoração de outros conteúdos de comunicação utilizados em redes sociais. Esse resultado traz um novo universo a ser explorado pela pesquisa em ciências e sua consequente intervenção no processo educativo. Segundo Tomaél, Alcará, e Di Chiara (2005), as redes sociais se constituem de um ambiente rico em elementos que podem ser utilizados no contexto de concepção como um tema que está sendo abordado pela sociedade e que pode ser utilizado no contexto da educação. Deve-se considerar que o conhecimento tem ultrapassado ambientes acadêmicos, científicos e didáticos, conquistando espaços em outras esferas, cujos usuários se aglutinam em objetivos específicos ou apenas pelo prazer de usufruir desse meio. Os autores ressaltam, ainda, que o espaço em que as redes sociais se constituem e proliferam são inerentes e de importância social e econômica e, consequentemente, causam um efeito na população. Por este motivo, a adesão em grupos e a identificação com determinadas postagens desencadeiam a necessidade e o prazer em compartilhar o conteúdo e, assim, buscar causar, de maneira imediata e visível, mudanças no meio. Essa inferência foi detectada no presente estudo devido ao elevado número de adesões e postagens relacionadas ao BEA. Assim, incentiva-se que a escola se aproprie do conteúdo, da linguagem e principalmente da motivação do estudante, resultante de um processo de identificação. Esta sugestão se apoia nas orientações de Patrício e Gonçalves (2010) de que as redes sociais suportam um espaço de interesses, necessidades e metas comuns para a colaboração, a partilha de conhecimento, a interação e comunicação e de Chervinsk e Souza (2012), quando ressaltam que o público que acessa os grupos sente-se livre para se expressar e expor suas ideias. Nesse contexto, percebe-se que a representatividade do animal no processo de comunicação, ainda que em um mesmo momento temporal, apresenta manifestações distintas de acordo com os interesses individuais, sobressaindo o papel na comunicação.

\section{O uso de imagens de animais}

O uso de imagens de animais no contexto secundário como coadjuvante do processo de comunicação verbal em todos os perfis analisados na rede social, endossa a função mimética dos elementos visuais da natureza. Segundo Ammann (2011), desde a Era Clássica, a afinidade mimética entre os homens e os animais é a dimensão central que fundamenta a possibilidade de uma concepção emancipatória da realidade, reforçada pela possibilidade de compartilhamento inerente às redes sociais. Esse resultado foi contra a expectativa inicial da utilização das redes sociais como espaço para denúncias, como auxiliar para encontrar animais perdidos ou para direcionar animais resgatados para adoção. Tais finalidades são menos frequentes do que as de decoração, exibição de animais de estimação, culto à natureza e sensibilização. Porém, mesmo diante do fato de esses propósitos terem se pronunciado nos últimos anos, o predomínio de compartilhamento de imagens de animais como canal de integração 
pode ser interpretado, segundo Chervinsk e Souza (2012), como promotores meio de aceleração do processo de comunicação. Desta forma, as imagens compartilhadas são decorrentes do interesse do internauta, refletindo processos inerentes à teoria da biofilia (Wilson, 1984), cuja demanda de interagir com elementos do mundo natural ultrapassou a realidade invadindo o meio virtual. Os usuários conectados em círculos colaborativos compartilham interesses, de modo que cada perfil apresenta uma combinação própria de utilização das imagens de animais reforçando os elos que mantêm a sua rede social em consonância. Desta forma, usuários da área da biologia se destacaram dos internautas das demais áreas pela pronunciada exibição dos seus animais de estimação e uso de imagens de animais para promover sensibilização e informação, além de congregarem praticamente a maioria dos registros de animais perdidos, denúncias, eventos e consumo e, evidenciando assim maior diversidade do uso de animais no processo de comunicação, inerente à área de formação. Ressalva-se que a sensibilização e denúncia também foram frequentes nos usuários das áreas de fotografia e história, igualmente endossando o processo comunicativo em suas áreas específicas. Esse é um resultado extremamente relevante para educação, uma vez que o modo como as pessoas percebem, identificam, categorizam e classificam o mundo natural influencia no modo como pensam, atuam e expressam emoções com relação aos animais, sendo o conhecimento da mesma um ponto de partida para programas de educação ambiental.

\section{Conceito de BEA por estudantes do ensino médio}

$\mathrm{Na}$ atividade do grupo focal e na produção artística e literária, tivemos evidências de que os estudantes do ensino básico que participaram da intervenção no presente estudo associavam o bem-estar animal aos animais com os quais conviviam. Os estudantes mostraram entender o papel ecológico dos animais, legitimando interações como predação, comensalismo, parasitismo, pois esses conceitos foram trabalhados desde o ensino fundamental da disciplinar curricular. Embora tenham expressado uma visão antropocêntrica utilitarista na relação com os animais, eles mostraram compreender que os seres humanos estabelecem interações injustas com os animais, utilizando argumentações relativas a níveis morais mais maduros segundo a escala de desenvolvimento moral proposta por Kohlberg (Biaggio, Vargas, Monteiro, Souza, \& Tesche, 1999). Embora a escala de nivelamento moral não tenha sido utilizada como parâmetro avaliativo no presente estudo, ficou evidente que mesmo diante da atribuição pelos estudantes da relevância do uso de tecnologias para as sociedades e do senso comum vinculado a uma crença de que os animais podem ser subjugados (Herculano, 2000), a maioria dos estudantes não endossou a concepção de novas tecnologias para produção de cosméticos e medicamentos, ressaltando a necessidade de descobertas de meios alternativos. A metodologia empregada no presente estudo corrobora as evidências de Biaggio, Vargas, Monteiro, Souza, e Tesche (1999) de que a aplicação de técnicas de dinâmica de grupo de resolução de problemas, pode ser um meio de estimular a maturidade moral. As intervenções investigadas pelos autores atestaram que a inserção de 
uma questão ética no contexto escolar gera automaticamente um conflito cognitivo que podelevar a desconfortos diante de opiniões mais maduras e, consequentemente, conduzir o estudante à reflexão dos parâmetros balizadores de seus julgamentos. Biaggio, Vargas, Monteiro, Souza, e Tesche (1999) balizaram suas avaliações na proposta de Kohlberg, sendo esperado que todos os indivíduos passem por três níveis de desenvolvimento moral: no primeiro, o certo e o errado são mediados pelas consequências físicas, logo pelo medo; no segundo nível, a conduta é adequada pelo julgamento social, ou seja, pela vergonha; no último, o indivíduo, transformado em sujeito, consegue direcionar um olhar para o outro e refletir sobre a justiça levando em consideração os seus próprios valores, isto é usando um referencial interno de julgamento. No entanto, a aplicação da metodologia ativa por meio de resolução de problemas nos adolescentes por Biaggio, Vargas, Monteiro, Souza, e Tesche (1999) resultou em um efeito modesto, o que segundo os autores foi decorrência da falta de motivação dos estudantes, provavelmente associada ao fato de os mesmos estarem focados em demandas fisiológicas e emocionais do seu próprio corpo, não conseguindo transcender para preocupações mais complexas como as de cunho ambiental. Esse resultado, deve ser tomado como parâmetro para incentivar os pesquisadores da área de educação em bioética a inserirem pré e pós testes em suas intervenções a fim de atestarem a efetividade no amadurecimento moral dos estudantes, assim como a desenvolverem mecanismos motivacionais para que que a criança e o adolescente se insiram como protagonistas em questões éticas de interesse social.

Por outro lado, Fraga e Borges (2010) relataram um caso de sucesso na aplicação de uma prática construtivista de aprendizagem participativa sobre conhecimento a respeito de ética animal, em uma turma de Educação de Jovens e Adultos (EJA) formada por um grupo heterogêneo, com distintas faixas etárias e objetivos de vida. Os autores ressaltaram a eficiência da técnica uma vez que o posicionamento inicialmente pobre e reflexo do senso comum de como se portar diante das questões sobre maus-tratos a animais foi substituído por visões aprofundadas, apontando legislação e órgãos responsáveis, sendo acompanhadas de explicações e pontos de vistas e evidenciando a importância da mobilização da sociedade e a necessidade de transformação. Fragada-Silva e Krasichik (2013) aponta a importância do investimento na formação de professores de ciências e biologia que ultrapasse os paradigmas tecnocráticos típicos das décadas de 1950 e 1960 e, ainda predominantes. Desta forma, defendem a valoração predominante dos aspectos cognitivos seja transposta para construção e evolução moral, mesmo diante das implicações éticas profundas originárias das ciências biológicas. A alegação de docentes de diferentes realidades quanto à maior dificuldade na aplicação de metodologias ativas como a problematização e os dilemas morais resume à falta de tempo. Para Fraga-da-Silva e Krasichik (2013), esse é justamente o motivo que conduz o professor a dar respostas imediatistas diante do questionamento dos estudantes sobre casos noticiados na mídia. Desta forma, ele não se mostra capaz de promover a reflexão, e principalmente no desenvolvimento da habilidade de ouvir o outro. Esse resultado reforça a necessidade de desenvolvimento de pesquisas em metodologias de ensino/ 
aprendizagem que promovam a inserção da bioética no contexto escolar tanto na capacitação dos docentes quanto na formação dos estudantes.

O posicionamento dos estudantes diante das assertivas, dispostas na tabela 2, demonstrou a necessidade do desenvolvimento de pesquisas sobre maneiras de trabalhar as percepções ambientais. Embora a compreensão de que os animais dependam uns dos outros tenha sido menor no $2^{\circ}$ ano da escola pública e a de que os homens dependem dos animais tenha sido menor no $7^{\circ}$ ano da escola pública, a totalidade dos estudantes concordou que as relações estabelecidas entre os animais se diferenciam das relações homem/animal. A partir desta evidência, é possível planejar as intervenções para promover a educação ambiental. Vieira, Silva, Dolino, Silva, e Silva (2011) entendem a educação ambiental como componente de uma nova cidadania abrangente, relacionada com novos paradigmas de relação homem/natureza, o que contudo demanda repensar o sistema educacional. Desta forma, a inserção da aprendizagem nas questões éticas cotidianas tem o potencial de tornar os conteúdos mais relevantes para o educando, pois sua aprendizagem faria parte da realidade, permitindo a aplicabilidade dos conhecimentos fora do ambiente escolar. Neste contexto, segundo os autores, a ecopedagogia não visa apenas aproximar as discussões do meio ambiente e de um novo modelo de sociedade para educação, mas sim para um amplo desenvolvimento sustentável. Este argumento é válido para este estudo, pois nas discussões os alunos mostraram curiosidade e atenção. Ressalta-se, contudo, que a efetividade do aprendizado pode ser comprometida caso não haja continuidade da ação. Tal posição se alinha com a de Colombo (2014) que ressalta que, para que as ações de educação ambiental ocorram não se faz necessário abandonar conteúdos curriculares, mas direcionar a temática visando a formação cidadã do indivíduo.

A análise do material de sensibilização produzido pelos estudantes mostrou que os estudantes da rede particular expressaram afetividade de forma mais significativa. Por outro lado, a categoria e a espécie, dos animais representados não apresentaram um padrão entre as séries ou a origem da escola. Este resultado reflete novamente a teoria da biofilia de Wilson (1984), segundo a qual a necessidade humana de interagir com elementos naturais perpassa necessidade de expressar a beleza estética, resultado do julgamento e percepção do belo, gerando, assim, a produção de desenhos acarretados de emoções pelos fenômenos estéticos (Sodré, 2007). Sax (2001) também ressalta que a forma como o ser humano utiliza e percebe os animais está intrinsicamente associada com seu passado evolutivo, capacitando-o à criação de um vasto sistema informacional das espécies e do ambiente, o que se traduz em saberes, crenças e práticas culturais. Assim, pode-se inferir que as atitudes humanas voltadas aos animais evoluíram bem antes das primeiras tentativas de representá-los nas artes, história e ciências. Logo, as evidências correspondem com a interpretação de Fischer e Tamioso (2013) para a relação entre acadêmicos de diferentes áreas do saber e animais. Os autores salientaram que complexas interações culturais podem ser abordadas por meio de distintos recortes, uma vez que que a percepção e interação com os múltiplos animais estão condicionadas 
à representação dos mesmos, a qual, além do componente cultural, pode ter um componente pessoal de empatia, levando à diferentes valorações de acordo com gênero, idade, nível socioeconômico, local de moradia e experiências prévias. Tais mecanismos devem ser explorados pelo educador como fonte motivacional para inserção do estudante na temática.

No presente estudo, não foi constatada influência do nível socioeconômico nos desenhos produzidos pelos estudantes, uma vez que tanto os animais de companhia quanto os de produção foram retratados por alunos de ambos os colégios. Contudo, enfatiza-se que animais na natureza e em ambientes livres foram mais representados por alunos do sétimo ano da rede particular. Para Menezes-Filho (2007), o baixo desempenho dos alunos do colégio público reflete a realidade de muitas instituições e caracterizam as desigualdades no ensino. Na presente pesquisa, pode-se ressaltar diferenças de acordo com a série, sendo que os estudantes do $7^{\circ}$ ano da rede particular e os alunos do $2^{\circ}$ ano da rede pública, foram os que participaram com mais entusiasmo da pesquisa. É importante pontuar que existem diferenças de forma geral na metodologia de ensino usada em ambas as escolas, resultante de um ineficiente sistema social por parte de muitas escolas públicas. Porém, este fato não pode ser considerado meio de exclusão destas escolas para atividades diferenciadas e que motivem os alunos a perceber realidades para os problemas socioambientais. Segundo Colombo (2014), a escola cidadã necessita atuar com a motivação dos estudantes, exercitando-os a refletir e exercer a cidadania de forma que suas atitudes sejam refletidas em prol do próximo e de si mesmos, com dignidade e justiça para todos, justamente para que o cidadão tenha autonomia e não se encontre em situação de vulnerabilidade diante da possibilidade de poder ser manipulado.

\section{Conclusão}

O presente estudo contribui para a recente área de pesquisa em Bioética e Educação ao discutir os resultados de intervenções educativas associadas com as fontes de informações disponíveis para o estudante construir o conhecimento necessário para reflexão e protagonismo diante de uma questão ética. A natureza multidisciplinar da Bioética permite sua utilização como um instrumento metodológico, o qual mesmo diante da óbvia necessidade de aplicação nas escolas, é incipientemente aplicada em pesquisas e intervenções no ensino básico. Os resultados obtidos no presente estudo endossam a importância da elaboração de metodologias que permitam a inserção da bioética e da educação ambiental na educação formal do ensino básico que possam contribuir para que o estudante se transforme em um cidadão autônomo, consciente, produtor e disseminador de conhecimentos e multiplicador de valores éticos necessários para construção de uma sociedade justa e igualitária, tanto com relação aos diferentes grupos sociais, quanto em relação aos animais e à natureza. A presente pesquisa caracterizou o universo de informações disponível para educadores e educandos o que pode dar suporte à construção de suas concepções a respeito da relação com os animais. A intermediação da bioética ambiental deve capacitar ambos a transitarem 
pela vasta congregação de argumentos identificando agentes, pacientes morais e vulnerabilidades, entre os atores que compõe um determinado problema gerado a partir do rápido e expressivo desenvolvimento tecnocientífico da humanidade. Embora nesse contexto as crianças e adolescentes assumam o papel de pacientes morais, muitas vezes vulneráveis diante das decisões de seus tutores, é justamente nesse momento do seu desenvolvimento cognitivo que estão sendo formadas as bases para o amadurecimento moral. As sociedades contemporâneas incapazes de decidir como se comportar diante do aumento da complexidade dos problemas, demanda cada vez mais a intervenção da escola, que pode cumprir o papel fundamental de munir os estudantes com ferramentas que os permitam compreender as informações disponíveis e, assim, a partir de um exercício reflexivo, serem capazes de ponderar os argumentos prós e contra que surgem diante de interesses específicos na solução de uma questão ética. Soma-se a esta reflexão a disposição de referenciais pautados em valores solidamente construídos por processos educativos envolvidos com a vida familiar, escolar e social, a fim de que o estudante possa se posicionar e tomar atitudes que venham de fato a contribuir para construção de uma sociedade ética e sustentável.

A promoção do bem-estar dos animais é uma conduta ética esperada de todo sujeito que decide manter um animal cativo sobre sua tutela, seja para alimentação, serviço ou companhia. Para tal, demanda-se uma atitude de alteridade e primor pelos seus interesses, mesmo quando esses são contrários aos interesses do ser humano, principalmente aqueles que são injustificáveis e supérfluos. Logo, é essencial a condução de pesquisas na área da educação em ciências para que sejam elaborados, aplicados e validados meios de se trabalhar a conduta ética de educadores e estudantes com relação à natureza, em diferentes níveis escolares, através da aplicação de metodologias ativas e inovadoras de ensino e aprendizagem. Igualmente se faz necessária a pesquisa sobre como e quando utilizar novas ferramentas de tecnologias de informação e comunicação de modo a se alcançar uma educação integral, que inclua os aspectos tecnológico, moral, ambiental, econômico e espiritual, previstos em documentos oficiais que intencionam, além da formação técnica, a formação do cidadão. Contudo, sabe-se que para alcançar tal demanda é preciso a colaboração de diferentes setores, seja nas esferas de políticas públicas, no oferecimento de logística, na formação continuada dos professores, na integração do currículo, na participação da escola e da comunidade e, principalmente, no estudo metodológico e científico dessas intervenções. Desta forma, sugere-se que sejam conduzidas pesquisas que avaliem e validem a implementação de comitês de bioética nas escolas como um meio eficiente do bioeticista intermediar o diálogo entre todos os atores, inseridos no ambiente escolar.

\section{Agradecimentos}

Os autores agradecem todos os estudantes que contribuíram para o desenvolvimento desta pesquisa. 


\section{Referências}

Ammann, M. (2012). Facebook, eu curto: uma análise mimética das redes sociais digitais. Mestrado em Educação Dissertação, Universidade de Brasília, Brasília.

Araujo, E. S. N. N., Tizioto, P. C., Caluzi, J. J., Batisteti, C. B., \& Andrade, A. M. C. (2010). Bioética e ensino: o que pensam os alunos do ensino médio sobre as pesquisas com células tronco embrionárias? São Paulo: Editora UNESP.

Araújo, M. C. M. U. (2009). Potencialidades do uso do blog em educação. Mestrado em Educação Dissertação, Universidade Federal do Rio Grande do Norte, Natal. Recuperado de http://bdtd.bczm.ufrn.br/tde_arquivos/9/TDE-2010-04-27T013000Z-2558/Publico/ MicheleCMUA.pdf

Bardin, L. (2004). Análise de conteúdo (3ª ed. Vol. 70). Lisboa: Edições.

Barzano, M. A. L. (2009). Uma ONG e suas práticas pedagógicas: uma contribuição para a educação não-formal. Revista entreideias: educação, cultura e sociedade, 14(15).

Bauman, Z. (2004). Amor líquido: sobre a fragilidade dos laços humanos. Rio de Janeiro: Zahar.

Bévort, E., \& Belloni, M. L. (2009). Mídia-educação: conceitos, história e perspectivas. Educação e Sociedade, 30(109), 1081-1102.

Biaggio, Â. M. B., Vargas, G. D. O., Monteiro, J. K., Souza, L. K. D., \& Tesche, S. L. (1999). Promoção de atitudes ambientais favoráveis através de debates de dilemas ecológicos. Estudos de Psicologia, 4(2), 221-238.

Brasil, L. d. M. P., Fisberg, M., \& Maranhão, H. d. S. (2007). Excesso de peso de escolares em região do Nordeste Brasileiro: contraste entre as redes de ensino pública e privada. Revista Brasileira de Saúde Materno Infantil, 7(4), 405-412.

Broom, D. M., \& Fraser, A. F. (2010). Comportamento e bem-estar de animais domésticos. (4 ed.): Manole.

Capilé, K. V., Lima, M. C., \& Fischer, M. L. (2014). Bioética ambiental: Refletindo o uso de fogos de artifício e suas consequências para a fauna. Revista Bioetikos, 8(4), 406-412.

Chervinski, R. A. (2012). A utilização de mídias sociais como complemento para ações de marketing: análise do caso ford e facebook. Revista Advérbio, 6(12).

Ciampi, M. (2005). O papel das ONGs de proteção animal e perspectivas para o controle da Leishmaniose Visceral. In Informe final de la Reunión de Expertos OPS/OMS sobre Leishmaniasis Visceral en las Américas (pp. 118-120). Rio de Janeiro: Panaftora.

Colombo, S. R. (2014). A Educação Ambiental como instrumento na formação da cidadania. Revista Brasileira de Pesquisa em Educação em Ciências, 14(2), 67-75. 
Dal-Farra, R. A. (2003). Representações de animais de companhia na cultura contemporânea: Uma análise na mídia impressa. Semiosfera, 3(7).

Fisher, M. L (2013). Utilização do blog como ferramenta didática no Ensino superior. Anais XI Congresso Nacional de Educação- EDUCERE.

Fischer, M. L., Caires, L. B., \& Colley, E. (2015). Análise das informações veiculadas nas mídias digitais sobre o Caramujo Gigante Africano Achatina fulica. Revista Brasileira de Pesquisa em Educação em Ciências, 15(1).

Fischer, M. L., \& Tamioso, P. R. (2013). Perception and position of animals used in education and experimentation by students and teachers of different academic fields. Estudos de Biologia: ambiente e diversidade, 35(84), 85-98.

Fischer, M. L., Renk, V., Rodrigues, G., \& Bordini, A. S. J. (2014). Interfaces entre a Bioética Ambiental e o Ecoturismo. Bioetikos, 8(4), 413-421.

Fraga, R. F., \& Borges, R. M. R. (2010). Bioética com animais: uma proposta para a educação de jovens e adultos no ensino médio. Experiências em Ensino de Ciências 5(1), 77-87.

Fraga-da-Silva, P., \& Krasilchik, M. (2013). Bioética e ensino de Ciências: o tratamento de temas controversos-dificuldades apresentadas por futuros professores de Ciências e Biologia. Revista Ciência e Educação, 19(2).

Francione, G. L. (2013). Introdução aos direitos animais: seu filho ou o cachorro. Campinas: Editora Unicamp.

Gohn, M. G. (2009). Educação Não-Formal e o Papel do Educador(a) Social. Revista Meta: Avaliação, 1(1), 28-43.

Grandin, T., \& Johnson, C. (2010). O bem estar dos animais: proposta de uma vida melhor para todos os bichos. Rio de Janeiro: ROCCO.

Harrison, R. (1964). Animal Machines. London: Stuart.

Herculano, S. C. (2000). ONGs e movimentos sociais: a questão de novos sujeitos políticos para a sustentabilidade. In UFF (Ed.), Meio ambiente: questões conceituais (pp. 123-155). Niterói.

IBGE, \& ABINPET (2013 ). População de animais de estimação no Brasil-2013-Em milhões. Recuperado de http://www.agricultura.gov.br/arq_editor/file/camaras_ tematicas/Insumos_agropecuarios/79RO/IBGE_PAEB.pdf.

Lei no 11.794, de 8 de outubro de 2008. (2008) Procedimentos para o uso científico de animais.

Lei $\mathrm{n}^{\circ}$ 9.605, de 12 de fevereiro de 1998. (1998) Dispõe sobre as sanções penais e administrativas derivadas de condutas e atividades lesivas ao meio ambiente, e dá outras providências. 
Levai, L. F. (2014). Crueldade consentida-crítica à razão antropocêntrica. Revista Brasileira de Direito Animal, 1(1).

Mantovani, A. M. (2006). Blogs na Educação: construindo novos espaços de autoria na prática pedagógica. Revista Prisma, 1(3).

Menezes-Filho, N. A. (2007). Os determinantes do desempenho escolar do Brasil. São Paulo: Instituto Futuro Brasil/ IBMEC.

Ministério da Saúde. Plano Nacional de saúde-PNS 2012-2015: Série B. Textos básicos de Saúde. (2011). (1 ed. Vol. 1). Brasília: Ministério da Saúde.

Moran, J. M. (1997). Como utilizar a Internet na educação. Ciência da informação, 26(2).

Patrício, M. R., \& Gonçalves, V. (2010). Facebook: rede social educativa? In I Encontro Internacional TIC e Educação. Lisboa: Universidade de Lisboa, Instituto de Educação. p. 593-598. ISBN 978-989-96999-1-5

Ministério da Educação (1997). PCN - Parâmetros Curriculares Nacionais para o Ensino Médio (PCNEM) Brasília: Recuperado de http://portal.mec.gov.br/programanacional-biblioteca-da-escola/195-secretarias-112877938/seb-educacao-basica2007048997/12598-publicacoes-sp-265002211.

Regan, T. (1983). The case for animal rights. Berkeley/LA: University of California Press. Ressel, L. B., Beck, C. L. C., Gualda, D. M. R., Hoffmann, I. C., Sehnem, G. D., \& Silva, R. M. D. (2008). O uso do grupo focal em pesquisa qualitativa. Texto \& Contexto Enfermagem, 17(4), 779.

Robis, M., \& Nassaro, F. (2013). Maus tratos aos animais e violência contra as pessoas: aplicação da Teoria do link nas ocorrências da Polícia Militar Paulista. São Paulo: Edição do autor.

Russo, K. (2013). Parceria entre ONGs e escolas públicas: alguns dados para reflexão. Cadernos de Pesquisa, 43(149), 614-641.

De Sá, J. B., \& Moraes, H. J. P. (2011). Mídia e Educação: reflexões, relatos e atuações. Revista Querubim, 2(1), 19.

Sabbatini, M. (2001). Qualidade da informação nas publicações científicas electrônicas na Internet: desafios e propostas. Teoría de la Educación: Educación y Cultura en la Sociedad de la Información, 1(2), 8.

Santana, L. R., Macgregor, E., Souza, M. F. D. A. E., \& Oliveira, T. P. (2004). Posse responsável e dignidade dos animais. Anais do $8^{\circ}$ Congresso Internacional em Direito Ambiental, 8(1), 533-552.

Sax, B. (2001). The Mythical Zoo: an encyclopedia of animals in world myth, legend, and literature: ABC-CLIO.

Singer, P. (2000). Libertação Animal. Rio de Janeiro: Ediouro. 
Sodré, L. G. P., Reis, I. T., \& Guttin, J. (2007). Análise dos elementos da natureza nos desenhos livres de crianças da Educação Infantil. Trabalho apresentado no VI Congresso Internacional de Educação, Concórdia Santa Catarina.

Tomaél, M. I., Alcará, A. R., \& Di Chiara, I. G. (2005). Das redes sociais à inovação. Ciência da informação, 34(2), 93-104.

Vieira, A. C. S. B., Silva, D. K. R., Dolino, M. S. F., Silva, T. F., \& Silva, V. F. (2011). Tecnologia na educação: O uso de software na abordagem da educação ambiental. Monografia, Universidade de Minas Gerais, Belo Horizonte.

Vygotsky, L. S. (2001). Psicologia da arte. São Paulo: Martins Fontes.

Wilson, E. O. (1984). Biophilia: Harvard University Press.

Animais, Seres Sencientes. (2011). Brasil: WSPA. Recuperado de http://www.youtube. $\mathrm{com} /$ watch?v=JJN6deox0hk.

Marta Luciane Fischer

http://orcid.org/0000-0002-1885-0535

Programa de Pós-Graduação em Bioética Pontifícia Universidade Católica do Paraná

Curitiba, Brasil

marta.fisher@pucpr.br

Ana Laura Diniz Furlan

http://orcid.org/0000-0003-3419-3456

Programa de Pós-Graduação em Bioética

Pontifícia Universidade Católica do Paraná

Curitiba, Brasil

ana.Idf@hotmail.com

Submetido em 06 de Novembro 2015

Aceito em 18 de Julho 2016

Publicado em 31 de Agosto de 2017 